Çukurova Üniversitesi Mühendislik Mimarlık Fakültesi Dergisi, 32(3), ss. 165-174, Eylül 2017

Çukurova University Journal of the Faculty of Engineering and Architecture, 32(3), pp. 165-174, September 2017

\title{
Halep Minarelerinin Rekonstrüksiyonu için Alternatif Yaklaşım
}

\author{
Abdullah BÜLBÜL ${ }^{* 1}$, Salah HAJ İSMAIL ${ }^{2}$, Rukiye ÇETİN ${ }^{3}$ \\ ${ }^{1}$ Ankara Yıldırım Beyazıt Üniversitesi, Mühendislik ve Doğa Bilimleri Fakültesi, Bilgisayar \\ Mühendisliği Bölümü, Ankara \\ ${ }^{2}$ Ankara Yıldırım Beyazıt Üniversitesi, Mühendislik ve Doğa Bilimleri Fakültesi, Inşaat \\ Mühendisliği Bölümü, Ankara \\ ${ }^{3}$ Ankara Yıldırım Beyazıt Üniversitesi, Mimarlık Fakültesi Mimarlı Bölümü, Ankara
}

Geliş tarihi: 09.06.2017 Kabul tarihi: 25.09.2017

$\ddot{\mathbf{O z}}$

Suriye'de altı yıldır devam eden yıkıcı savaş kültürel miras niteliğindeki sit alanlarını tahrip etmiş, değerli tarihi yapıların kısmi olarak ya da tamamen yok olmasına sebep olmuştur. Dünya mirası sit alanlarından biri olan Halep şehri, İslam mimarisinin farklı dönemlerine uzanan ve o dönemleri belgelendiren minareler gibi birçok önemli ve eşsiz tarihi yapısını -bu savaş sebebiyle- kaybetmiştir. Bu minarelerden birisi de 25 Nisan 2013'de yok edilen Halep Emevi Cami (Halep Ulu Cami)'ne aittir.

Neyse ki, minarelerden birçoğu gelecekte rekonstrüksiyon imkânı sağlayacak fotogrametrik verilerle belgelendirilmiştir ve Emevi Cami'nin minaresi bunlardan birisidir. Bu çalışmayla yıkılan yapıların rekonstrüksiyonu için artırılmış sanal gerçeklik tekniklerini kullanarak alternatif bir yöntem önerilmiştir. Öncelikle sözü edilen fotogrametrik verilerle üç boyutlu (3B) modeller otomatik olarak oluşturulacak ve sonrasında özgünlük, tersine çevrilebilirlik gibi uluslararası rekonstrüksiyon sözleşmelerindeki öneriler göz önünde bulundurularak sanal olarak (yapı arsasında) inşa edilecektir.

$\mathrm{Bu}$ yöntemin sunacağı imkânlar ve sebep olacağı sorunlar tartışılıp, simgesel minareler üzerine karşılaştırmalı örnek çalışmalar gerçekleştirilecek, bu çalışmanın savaştan etkilenen diğer tarihi eserler üzerine de genişletilmesi için olanaklar araştırılacak ve bu yöntemin Suriye'de tahribata uğramış bütün tarihi eserler için sadece turist fotoğrafları üzerinden uygulanabilirliği değerlendirilecektir.

Anahtar Kelimeler: Minare, Halep, Artırılmış Gerçeklik, Rekonstrüksiyon

\section{Alternative Approach for Reconstruction of Aleppo Minarets}

\begin{abstract}
A six years destructive war in Syria has damaged many of the heritage sites, causing partial or total loss of invaluable monuments. Aleppo, one of those world heritage sites in Syria, has lost -due to this warmany important and unique monuments of the old city, such as the mosques' minarets dating and documenting different eras of Islamic architectural heritage, one of them is the minaret of Aleppo Umayyad mosque (the great mosque) destroyed on April $25^{\text {th }} 2013$.
\end{abstract}

"Sorumlu yazar (Corresponding author): Abdullah BÜLBÜL, abulbul@ybu.edu.tr 
Fortunately, many of those minarets have metric photographic documentation, and Umayyad minaret is one of them, that facilitate future reconstruction. An alternative approach was offered for on-site future reconstruction using augmented virtual reality techniques, firstly creating Auto generated 3D models by using previously mentioned image documentation, and then virtually reconstruct the minaret (in-situ) as an alternative compatible with international charts recommendations for reconstruction such as reversibility and authenticity.

This approach opportunities and threats are discussed, and comparative case studies were applied on iconic minarets, seeking to investigate the possibility of widening this practice to cover other affected monuments, solely documented by tourists' photos, in order to implement this methodology on all the damaged heritage by Syrian war in the future.

Keywords: Minaret, Aleppo, Augmented reality, Reconstruction

\section{GİRIS}

Hz. Muhammed (S.A.V.) döneminde inşa edilmemesine rağmen Minare ya da Arapça Mi'dhana, cami tasarımında yer alan önemli unsurlardandir [1]. Esas olarak ezan okumak -ibadete çağrı- amacıyla cami mimarisine eklenmiştir. Zaman içinde taşıyıcı sistem ve biçimsel olarak gelişmeler göstererek mimari unsur olarak simgeleşmiştir [2]. İlk kare planlı Emevi minarelerinden kalem tipi Osmanlı minarelerine kadar, artık yalnızca minarelere bakarak caminin tarihi ve üslubu hakkında fikir edinebilmek mümkündür.
Emevi

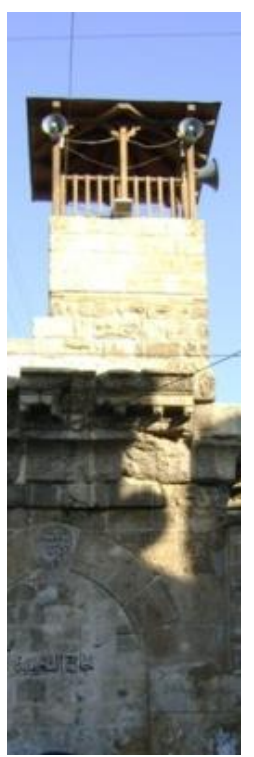

Zengi

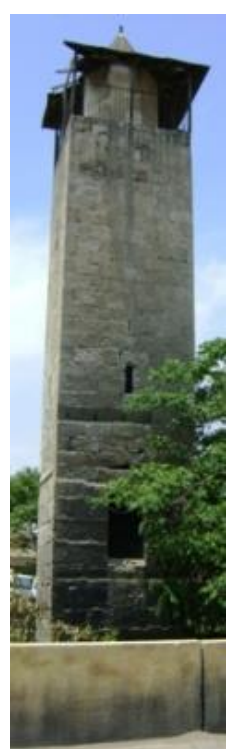

Eyyubi

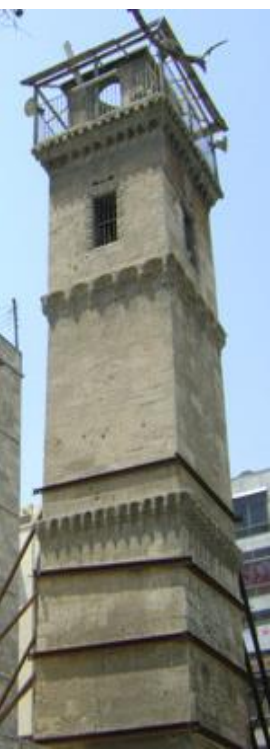

Moğol

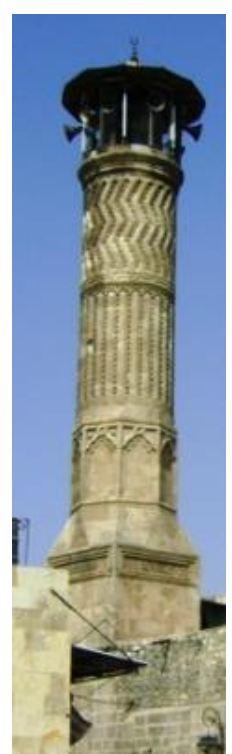

Memluk

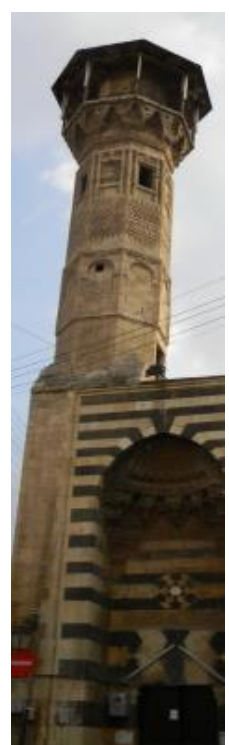

Osmanlı

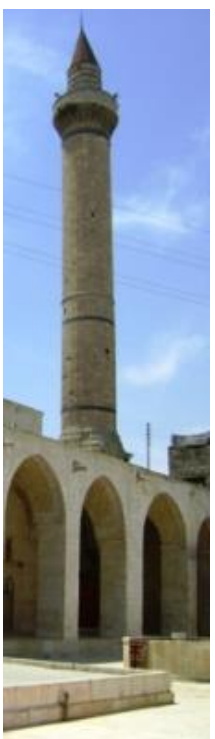

Şekil 1. Halep’te Minare üsluplarının kronolojik olarak gelişimi, soldan sağa doğru Emevi, Zengi, Eyyubi, Moğol, Memluk ve Osmanlı üslupları ile inşa edilmiş minareler

En eski yaşayan yerleşim merkezlerinden ve dünya mirası sit alanlarından biri olan 2006 yılı İslam kültürünün başkenti [3] Halep, cami ve minare mimarisine etkisini göstermiş çeşitli İslam medeniyetlerine ev sahipliği yapmıştır ve farklı mimari üslupları yansıtan eşsiz örnekleri bir arada sunmaktadır. 
Her ne kadar ses ve akustik teknolojisinin gelişimi ile minarelerin ezan işlevi azalsa da [4], simgesellik vasfi ve mimari değer olarak işlevi tarih sürecinde artmıştır. Halep Emevi Cami'nin minaresi bir şehrin kimliğini temsil etmek açısından oldukça iyi bir örnektir. Halep şehri özellikle kalesi, Emevi Cami ve dünya üzerindeki en eski minarelerden biri olan minaresiyle tanınmaktadır. Minarenin savaş sırasında yıkılmış olması insanlık ve muhakkak ki Halepliler için büyük bir kayıptır [5].

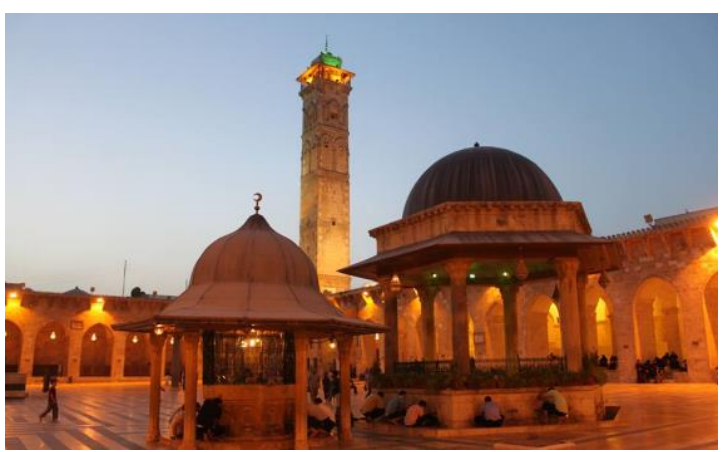

Şekil 2. Halep Ulu Cami ve minaresi 2009

Suriye'de altı yıldır devam eden savaşın ardından, Halep eski kent merkezinin kazara veya kasten vuku bulan yıkımı, yüksek değer arz eden tarihi yap1 kalıntılarının korunması, restorasyonu ve rekonstrüksiyonu için müdahale çalışmalarına olan ihtiyacı ortaya çıkarmıştır [6]. Bu çalışmalarda oluşabilecek ikilem hızlı ve itibar edilebilir rekonstrüksiyonun; aynı anda hem uluslararası sözleşmelerdeki özgünlük, geri alınabilirlik ve sürdürülebilirlik önerilerini hem de ulusal hukuk gereksinimlerini karşılayabilmesidir [7].

$\mathrm{Bu}$ makalede Halep Emevi Camii'nin yıkılan minaresinin rekonstrüksiyonu için yukarıda belirtilen hedefler doğrultusunda, teknolojik ve ekonomik imkanlar da göz önünde bulundurularak farklı bir yöntem sunulmuştur. $\mathrm{Bu}$ yöntem artırılmış gerçeklik teknolojisinden yararlanarak minarenin ası mekanında sanal olarak rekonstrüksiyonunu temel almaktadır. $\mathrm{Bu}$ doğrultuda rekonstrüksiyon sürecinde karşılaşılması muhtemel zorluklar ve çözüm önerileri de makalede tartışılmıştır. Sunulan sanal ve yerinde rekonstrüksiyon yöntemi, Haleplilerin minare ve diğer tarihi yapıların gelecekteki gerçek fiziksel inşaatları hakkında sunulan alternatifleri gözlemleyip fikir beyan ederek, yeniden inşa sürecine etkin bir şekilde katılmalarına da imkan sağlayacaktır.

\section{YÖNTEM}

Suriye'nin şu an savaş halinde olması ve tahrip olan kentlerle birlikte tarihi yapıların da fiziksel açıdan zarar görmesi, yapıların bütünselliğinin bozulması ve güvenlik sorunu gibi sebepler yüzünden üç boyutlu rekonstrüksiyon çalışmaları için sınırlı miktarda görsel veriye ulaşılabilmiştir. Ayrıca, yıkılan parçaların halen yapı üzerinde ve çevresinde olması tarihi yapının ana hatlarıyla algılanmasını ve program üzerinde tanımlanmasını güçleştirmektedir. $\mathrm{Bu}$ nedenle yine bütünlüğü bozulmuş ancak gerekli görsel malzemeye daha kolay erişimin sağlanacağı bir yapı arayışına gidilerek farklı olasılıklar, firsatlar ve zorlukların daha iyi analiz edilebilmesi adına, Halep minaresi üzerine yaptığımız çalışma Konya'dan başka bir örnek 'İnce Minareli Medrese' ile karşılaştırılmalı olarak yürütüldü.

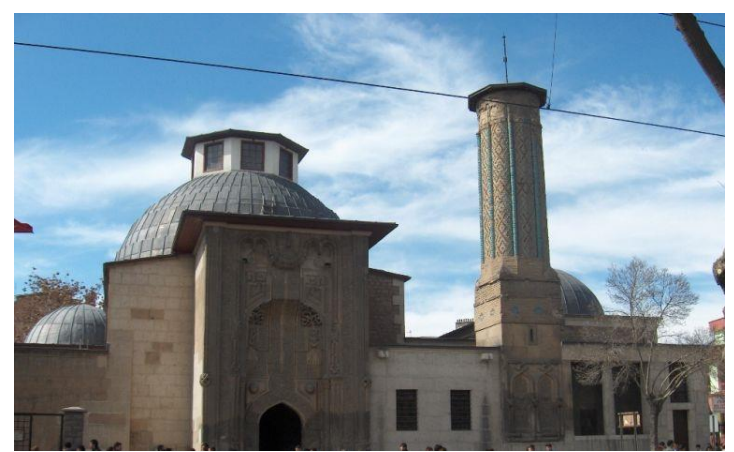

Şekil 3. İnce Minareli Medrese

1265 yılından önce yapımı tamamlanan İnce Minareli medrese Anadolu Selçuklu Döneminin özgün örnekleri arasında [8] olmakla birlikte inşası Halep Emevi Cami minaresinin Selçuklu Döneminde rekonstrüksiyonu ile aynı döneme tekabül eder. Emevi Cami minaresi 2013'te 
bombalanma sonucu tamamen y1k1lirken, İnce Minareli Medrese de 1901 yılında yıldırım düşmesi sonucu ilk şerefeye kadar yıkılmıştır [9]. Minare gövdesinin ve bu bölümdeki merdivenlerin geniş tuğla örgü ile inşa edilmesi, çatkı elemanlarının da ahşap malzemeden oluşması İnce Minarenin sarsıntılara olan dayanımını azaltmıştır [10]. Medrese külliyesinin restorasyonu sırasında (1936-1956) cami rekonstrüksiyon edilmiş, ancak minare ilk şerefeye kadar onarım görmüştür [11]. Emevi Cami ise 2003 yllındaki cami restorasyon projesi kapsamında restore edilmiştir.

\section{1. İlgili Çalışmalar}

Geçtiğimiz on yılda gelişen Artırılmış Gerçeklik (AG) teknolojileri, inşaattan oyun ve eğitim sektörüne kadar birçok alanda uygulanmaktadır [12]. AG, bu çalışmada ilk olarak belgelendirme amaçlı 3B görüntü elde etme çalışmalarında uygulandı. Örneğin, küresel fotogrametri, metrik belgeleme yöntemi olarak Emevi Cami Minaresinin ölçülerini ve mimari geometrik biçim verilerini elde ederek minarenin 3B modelini oluşturmak amacıyla kullanıldı [13]. Cep telefonları gibi GPS, jiroskop ve standart webkamerası özellikleri olan kişisel mobil cihazlar, coğrafi konum bilgisine ulaşmak için uygun ortamı oluşturur. $\mathrm{Bu}$ verinin haritalar ve internet üzerinden erişilebilen uydu ortofotoları ile karşılaştırılarak kullanılması, küçük tarihi eserler ve nesnelerin iç mekân restorasyonuna imkan sağlamakta olup, bu yöntem özellikle müze ve sanat galerilerinde cep telefonları üzerinde çalışan Augment (http:/www.augment.com/) ve benzeri uygulamalarda kullanılmaktadır [14]. Aynı teknolojinin daha büyük ölçekli projelerde uygulanabilirliği, yapısal detay miktarının oldukça artması ve dış mekandaki yüksek isabetli coğrafi konumlandırma ihtiyacından dolayı, düşmektedir [15].

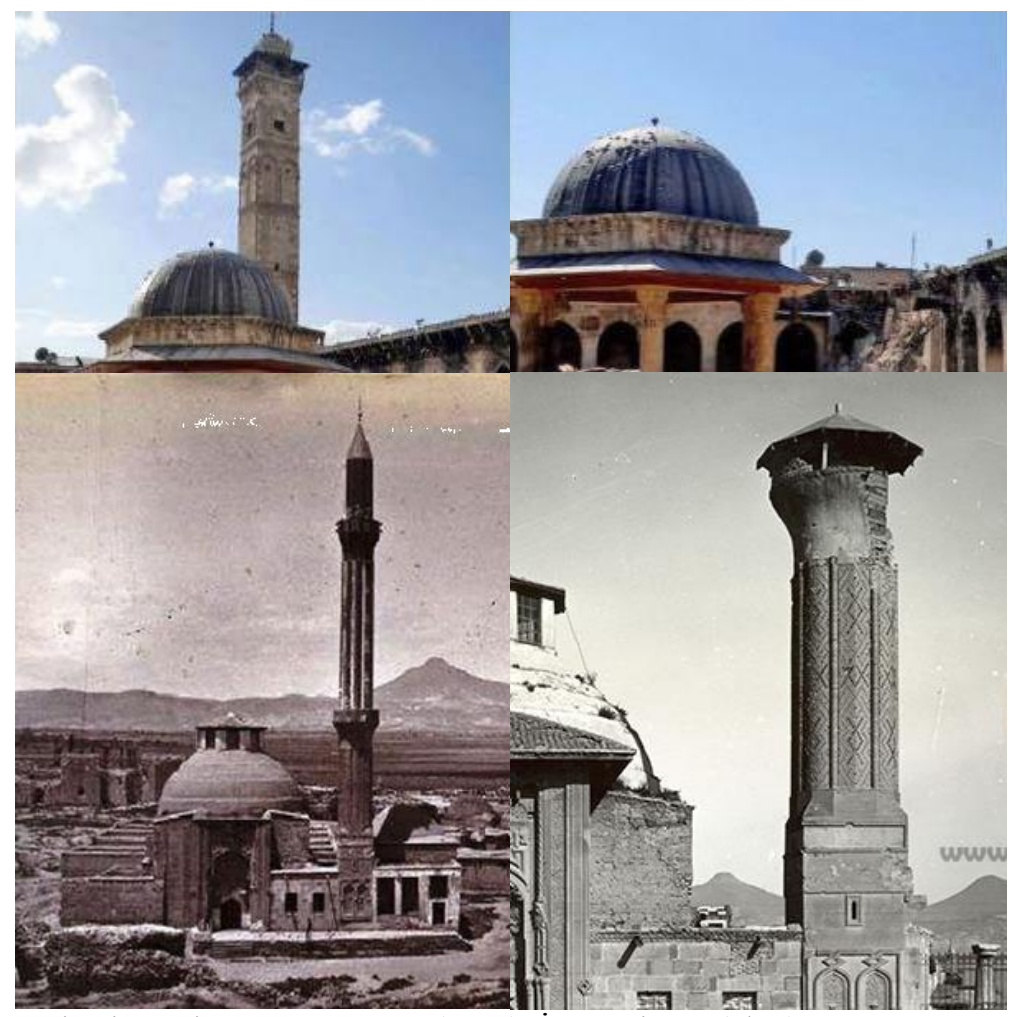

Şekil 4. Emevi Cami Minaresi önce ve sonrası (üstte), İnce Minare (altta) 
Bu çalışmanın önemli bir parçası da yapının sanal olarak 3B rekonstrüksiyonudur. 3B modeller Blender (https://www.blender.org/) ve Autodesk 3ds Max (http://www.autodesk.com/products/3dsmax/overview) gibi çeşitli programlarda kullanıcı tarafından oluşturulabilmektedir, ancak bu tür $3 \mathrm{~B}$ modelleme araçları sarf edilen zaman ve emek açısından elverişli değildir. Literatürde otomatik veya yarı-otomatik 3B rekonstrüksiyonu konu alan çalışmalar mevcuttur. Bir alanın farklı açılardan çekilmiş çok sayıda fotoğrafinın bulunması durumunda Hareketten Yapı Çıkarımı (Structure from Motion, SfM) olarak adlandirılan bir yöntemle çekimlerin yapıldı ̆̆ 3B nokta bulutları inşa edilir [16,17]. Poisson Rekonstrüksiyon gibi bir 3B mesh yüzey üretim metodu ile bu bulutlar yüzeylere çevrilir $[18,19]$. $\mathrm{Bu}$ yöntemler fotoğrafların çokluğuna ve kalitesine bağlı olup revaçta olan turistik alanlar için oldukça uygundur [20]. Yapının genel hatlarıyla geometrisi biliniyorsa, fotoğrafların model yüzeylerine yansitılmasına dayanan yöntemlerle daha az fotoğrafla 3B modelin oluşturulması da mümkün hale gelir [21]. Bunlara ek olarak fotoğraflarda paralel doğrular ve kaçma noktalarının tanımlanması ile yapının muhtemel yüzeylerinin tespiti ve bu muhtemel yüzeylerden doğru olanlarının kullanıcı tarafından belirlenmesine dayanan etkileşimli 3B rekonstrüksiyon yöntemleri de mevcuttur [22]. Bir diğer ilgili çalıșma da GPS ve tarih verileri ile işaretlenmiş fotoğraflarla zaman içinde mekânlar üzerinde yapılan değişikliklerin tespiti üzerinedir [23].

\subsection{Proje}

Geçmişte gerçekleştirilen restorasyon projelerinden ve arşivlerde bulunan planlar, kesit çizimleri ve görsellerden elde edilecek verilerle eserlerin farklı tarihi dönemlere ait 3B modellerini oluşturmak mümkündür. Daha sonra kamera ve GPS işlevi olan herhangi bir mobil cihaz vasitasiyla, internetin olmasi durumunda sunucudan indirilen, aksi takdirde cihaza daha önceden yüklenmiş olan 3B modeller kameranın konumu ve bakış açısının tanımlanmasıyla, gerçek konumlarında ve gerçek arka planları ile görüntülenebilecektir. Projede minarenin tarih boyunca değişen halleriyle görüntülenebilmesi amaçlanmış ve kullanıcının bu sayede tarihin farklı dönemlerinde minarenin yapısal değişimini ve zaman içinde eskiyen malzemeleriyle birlikte minareyi inceleme firsatı bulması hedeflenmiştir. Görüntünün yakınlaştırılması, tarihi bilgilerin eklenmesi, hatta Müezzinin minareye çıkışının ve ezan okumasının animasyonu gibi özelliklerle uygulamayı donatmak da sunulabilecek seçenekler arasindadir.

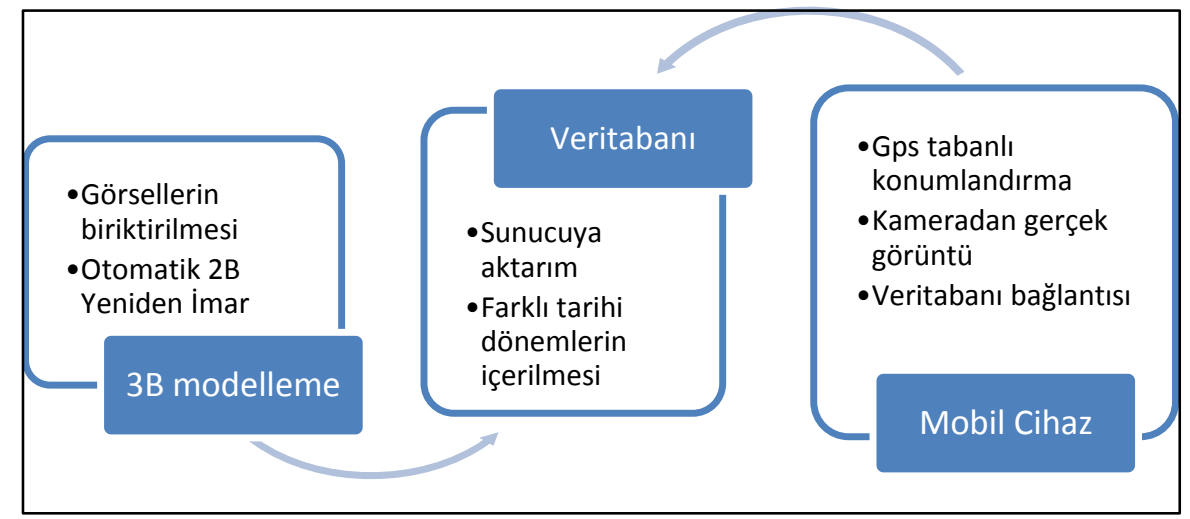

Şekil 5. Sanal ortamda rekonstrüksiyon AG kullanımı ve mobil cihazlarda gösterimi sürecinin diyagramı

\subsection{Kullanılan Teknoloji}

Mobil cihazların ekranlarında görüntülenebilecek şekilde sanal ortamda rekonstrüksiyonu sağlamak için öncelikle kayıp bölgelerin 3B modellerinin oluşturulması gerekmektedir, bunun için de farklı yöntemler mevcuttur. Bunlardan bir grubu birçok fotoğraf kullanarak otomatik 3B modelleme 
sağlayan SfM temelli yöntemlerdir. Şekil 6'da Flickr ve Google'da bulunan fotoğraflarla oluşturulmuş örnek bir 3B model sunulmuştur. Fotoğrafların niteliği ve niceliği modellemeyi doğrudan etkiler. Bu yöntemde yapının en çok dikkat çeken (turistler için en popüler olan) ve genellikle fotoğraflarda en görünür olan kısımları daha iyi modellenirken, daha az dikkat çeken kısımlarında sonuçlar o kadar iyi olmaz. Bu özellik yapının daha iyi modellenen popüler kısımlarının görsel açıdan da daha önemli olduğu fikri ile desteklenebilse de, yapının az fotoğraflanan kısımları son 3B modelde eksik bölgeler bırakabilir, bu da çoğu zaman kabul edilebilir bir durum değildir. Otomatik $3 \mathrm{~B}$ modellemenin diğer bir dezavantajı da, üretilen modelin nokta bulutu halinde olmasından dolayı, sonraki aşamada nokta bulutu üzerine oluşturulan yüzeyin bilhassa düşük nokta yoğunluğuna sahip kisımlarında gözle görülür hatalar bulunması riskidir.

Modellenmek istenen bölgenin daha az sayıda fotoğrafına erişilebildiği durumlar için, kullanıcının interaktif olarak yönlendirebildiği yarı otomatik modelleme yöntemleri de mevcuttur. Otomatik rekonstrüksiyon yöntemlerinde olduğu gibi SfM yöntemleri ile seyrek nokta bulutu oluşturulmasının ardından, sistem kullanıcıya muhtemel düzlemleri sunar ve kullanıcının seçimine göre modelin yüzeyi oluşturulur. Oluşturulan yüzey üzerine doku kaplanması için de kullanılan fotoğraflardan yararlanılır.

Son olarak, eğer farklı fotoğraflarda görüntü işleme yöntemleri ile eşleştirilebilen özellikler 3B model oluşturulması için yetersiz kalıyorsa, yazılı ve görsel açıklamalara bağlı olarak 3B model kullanıcı tarafindan 3B modelleme yazılımları kullanılarak oluşturulabilir. Görüntülerin ya da yazılı belgelerin varlığı, fotoğrafların kalitesi gibi eldeki verilerin özelliklerine göre, $3 \mathrm{~B}$ modelleme için, önerilen yöntemlerden uygun olanını ya da bu yöntemlerin karışımını kullanmak gerekebilir.

\section{BULGULAR}

İnce Minare ve Emevi Camii'nin minaresi bazı özellikleri açısından örtüşseler de, projenin Emevi Camii minaresine uygulanması için farklı kısıtlamalar mevcuttur. İnce Minareli Medrese için yaklaşık 10 metre hata payıly konum bilgisi sağlayan GPS hizmetleri [24] ve 4G internet kullanılabilir durumdadır. Buna ek olarak, medresenin önündeki geniş alan minarenin farklı açılardan görüntülenmesine imkan sağlar. Halep içinse, GPS içeren cihazlar güvenlik gerekçesiyle yasaklanmıştır ve minarenin bütünüyle yıkılmış olması uygulanabilecek teknolojileri kısıtlamaktadır. Ayrıca, caminin etrafındaki dar sokaklar minarenin şehrin farklı noktalarından bütün olarak görülmesini engellemektedir. Yıkılmadan önce çekilmiş birçok fotoğrafının olması ise Şekil 6'da görüldüğü gibi otomatik rekonstrüksiyonu mümkün hale getirir ve Emevi Camii minaresi için bir avantaj olarak sayılabilir. Daha önce bahsedildiği gibi, minarenin daha yaygın olarak fotoğraflandığı cami avlusuna bakan tarafi modellenebildiği halde, yeterince fotoğrafi bulunmayan tavan ve diş cepheler yeterli şekilde oluşturulamamıştır. Bundan dolayı, yarı otomatik bir rekonstrüksiyon yönteminin kullanılması daha uygun olacaktır.

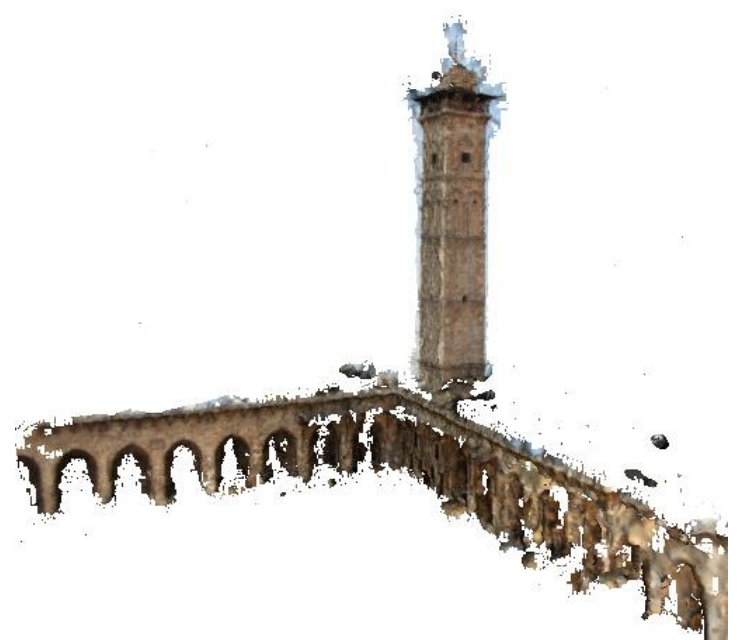

Şekil 6. Emevi Camiinin Flickr ve Google görsellerinden elde edilen fotoğraflar ile VisualSFM [25] kullanılarak elde edilmiş 3 boyutlu modeli

İnce Minare için de farklı zorluklar vardır ve bunlardan en önemlisi, minarenin yüz yıldan daha önce yıkılmasına bağlı olarak, sağlam halinin fotoğraflarının bulunmayışıdır. Bundan dolayı 
eksik kısmın tarihi doküman ve açıklamalara göre modellenmesi için 3B modelleme programlarına ihtiyaç duyulmaktadır.

İlgili alanın 3B modelinin elde edilmesinden sonra, ikinci aşama bu 3B modelin kamera görüntüsü üzerine doğru bir şekilde yerleştirilmesidir. Mimari eserlerin coğrafi koordinatları zaten bilinmekte olduğundan model ve çekilen görüntüyü eşleştirmek için çekilen görüntünün konum ve bakış açısını belirlemek gerekir. Kaba bir konum bilgisi, mümkün olduğunda GPS sinyallerinden elde edilebilse de Halep için durum böyle değildir. GPS bilgisinin eksikliğini telafi etmek amacıyla, caminin yaygın olarak fotoğraflandığı konumlar önceden belirlenir ve bu konumlara ait önceden biriktirilen görüntüler, kamera görüntüsü ile kıyaslanarak kullanıcının gerçekte hangi konumda olduğu belirlenir. $\mathrm{Bu}$ yöntem, GPS kullanılarak erişilebilecek konumlandırma isabetine görüntüleri kıyaslama maliyeti karşılığında ulaşılabilmesini sağlar.

3 boyutlu sanal modelin, kamera görüntüsü üzerine doğru şekilde yerleştirilebilmesi için konumlandırmanın önceki paragrafta bahsedilenden daha isabetli olarak gerçekleştirilmesi gerekir ki bu da kamera konumlandırmanın hata payını metrelerden santimetrelere indirmeyi hedefleyen sonraki aşamasını oluşturur. Oluşturulan üç boyutlu modelin, kamera görüntüsü üzerine belirgin bir hata olmaksızın yerleştirilmesi için görsel özelliklerin otomatik olarak bulunup bağdaştırılması gerekir. Böyle amaçlar doğrultusunda çokça yararlanılan görsel özellik belirleme yöntemlerinden biri SIFT (Scale-invariant feature transform)'tir [26]. SIFT özellikleri kullanılarak görsellerin ilişkilendirilebilmesi içinse her iki görselde de yer alan özgün görsel elemanlara ihtiyaç vardır. İlgilendiğimiz durumda ise eserin büyük bir kısmı hasar gördüğünden, oluşturulmuş modeldeki görsel ögelerin sınırlı bir kısmı halihazırda var olan kalıntılar üzerinde mevcuttur, bu da görüntüyü resmin üzerine yerleştirme işini zorlaştırmaktadır.
Konumlandırmanın iyileştirilebilmesi için kullanılabilecek bir diğer yaklaşım, görüntüdeki düz çizgilerden faydalanmaktır. Perspektif bakışa göre paralel çizgiler ufuk noktası (vanishing point) denilen bir nokta üzerinde birleşir. Eşleştirilebilir görsel özelliklerin tahribat sonucu azalmasına rağmen, geriye kalan düz çizgilerden ve ufuk noktalarından, oluşturulan modelin kamera görüntüsü üzerinde konumlandırılması için faydalanılabilir.

Kullanılabilecek bu teknolojiler, kısmen hasar görmüş kültürel miras eserlerinin geçici restorasyonuna dair projeler için yeni bir yaklaşımı mümkün hale getirir. Karmaşık, uygulanması zor ve pahalı fiziksel rekonstrüksiyon yerine sanal ve artırılmış gerçeklik teknolojileri ile gerçekleştirilen rekonstrüksiyon, zaman ve maliyet yükünü hafifletecektir. Ayrıca bu yöntem, gerçek uygulama öncesinde planlanan yöntemin yerinde analizini ve ihtiyaç halinde değişikliklerin yapılmasını mümkün hale getirir. Sunulan yaklaşımın bir başka avantajı da, eserin tarihi belgelere göre oluşturulabilecek farklı dönemlerdeki hallerini görüntülemeye imkan vermesidir.

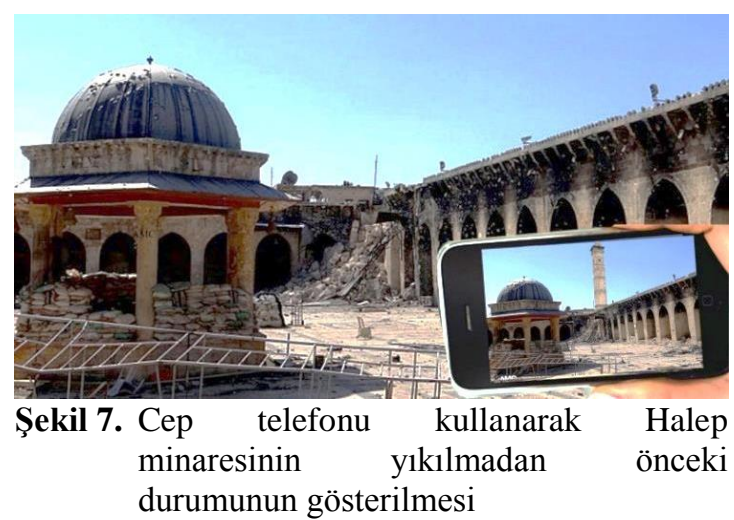

Sunulan projede, sanal rekonstrüksiyon yaklaşımının yüksek öneme sahip eserlerin fiziksel olarak rekonstrüksiyonuna geçerli bir alternatif oluşturduğu gösterilmektedir. Teknolojinin uygulanması için her farklı eserin özel şartları ve fiziksel durumuna göre birçok zorlukla yüzleşilmektedir. 


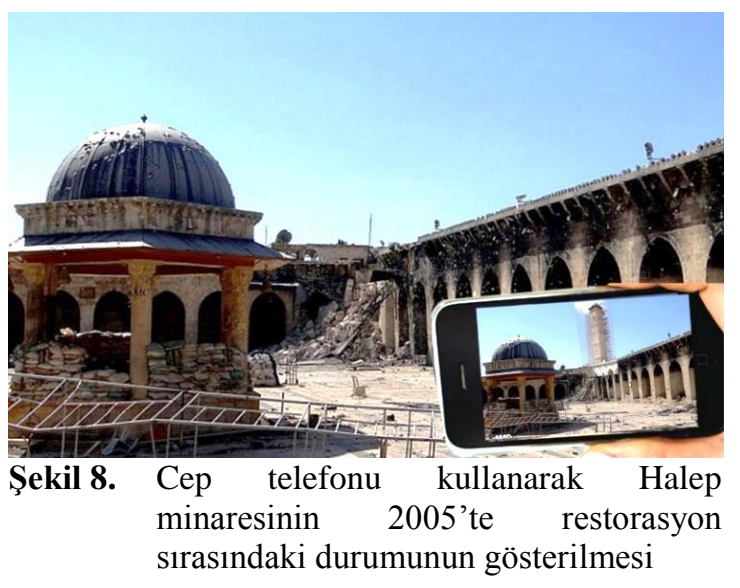

Projenin 3B modelin yeniden oluşturulması, oluşturulan modelin konumlandırılması ve kamera görüntüsü üzerine doğru şekilde yerleştirilmesi gibi her adımı için ulaşılabilen bilgilere ve fotoğraf, çizim, plan gibi belgelere bağlı olarak farklı yöntemlerden yararlanmak mümkündür. Turist, tasarımc1, karar vericiler gibi son kullanıcılara gerçek bir tecrübe edindirebilmek için her bir esere ayrı ayrı yaklaşılmalı, eserin hususi zorlukları ve kısitlamaları uzmanlarca kapsamlı ve derinlemesine yürütülen çalışmalara belirlenmelidir.

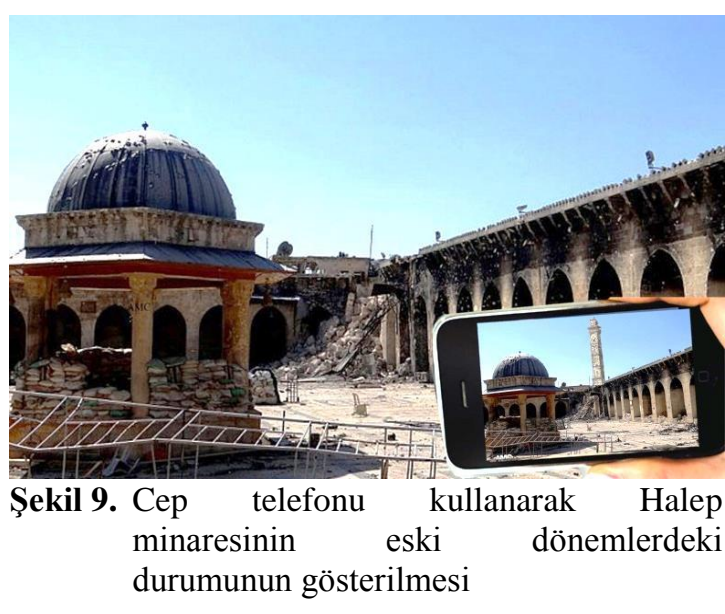

Bu projede farklı hususiyetlere sahip Halep Emevi Camii ve İnce Minareli Medrese üzerinde edinilen tecrübe ile benzer yöntemleri kısmen hasar görmüş başka eserlere uygulamak daha kolay olacaktır.
Örneğin, Şekil 11'de gösterilen Halep'teki Alrumi Camii yöntemin uygulanabileceği bir başka eserdir. $\mathrm{Bu}$ eser; minaresinin kismen zarar görmesi, inşa edildiği dönem ve mimari özellikleri açısından İnce Minareli Medrese'ye, görüş açısının kısıtlı olması ve teknolojik imkanlar açısından ise Halep Emevi Camii'ne yakın özellikler barındırmaktadır.

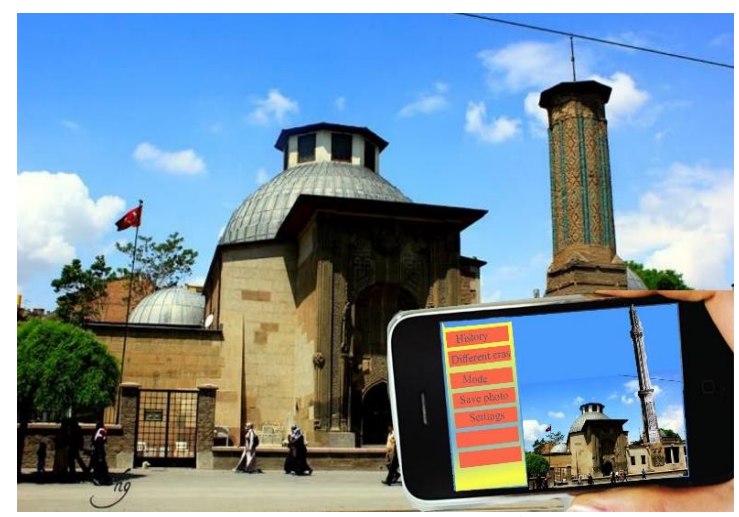

Şekil 10. Cep telefonu kullanarak İnce Minarenin tamamının 3B olarak uygulama seçenekleri ile birlikte görüntülenmesi

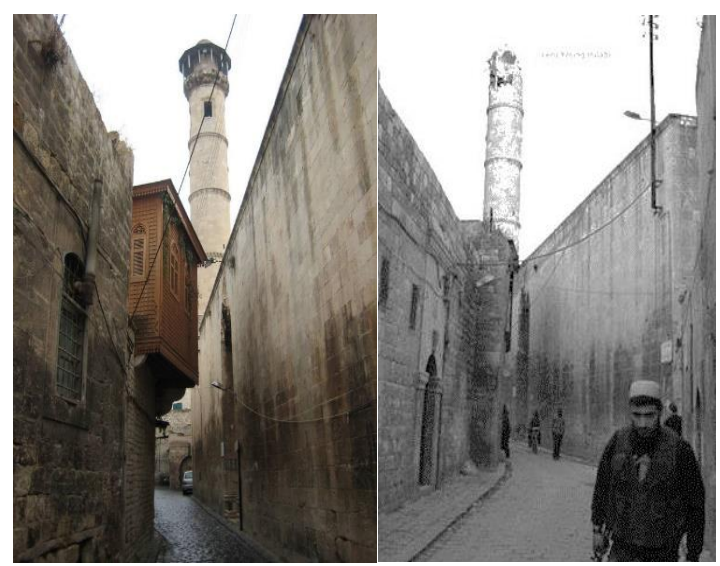

Şekil 11. Halep Alrumi Camii Minaresi. Hasar görmeden önceki hali (solda), sonraki hali (sağda)

Az sayıda görsele sahip ve tamamen yıkılmış tarihi eserler daha zorlu şartlar teşkil eder; özellikle düşeyde kimlik kazanmış yapıların 3B modellenmesi oldukça zordur. Yatay elemanların ve yapıların modellenmesinde karşılaşılabilecek 
sorunlar ve sınırlamalar ileriki çalıșmalarda değerlendirilecektir.

\section{SONUC}

$\mathrm{Bu}$ çalışmayla zarar görmüş tarihi yapıların kendi arazilerinde rekonstrüksiyonuna firsat veren, uluslararası sözleşmelerdeki koruma tavsiyeleri ve yöntemlere uygun, yapıların detaylı belgelendirilmesi ve analizlerinin yapılmasina kadar geçici çözüm sunan farklı bir yöntem sunulmuştur. Sunulan yöntem kullanıcıya 3B modeli yeni elde edilen bilgiler 1şığında güncelleme imkanı veren esnek bir çözüm olmakla birlikte, farklı tarihi dönemlerde yapının geçirdiği değişiklikleri de gösterebilir. Ayrıca gerçek imarın karmaşı, uzun ve maliyeti yüksek bir süreçten geçeceği tarihi eser ve kültürel miras alanları için de geniş çapta kullanım vadetmektedir.

Ayrıca önerilen yöntem tarihi alanların canlanması sağlayan, kişisel arşiv fotoğrafları ve belgelerin yüklenmesini ve toplanmasını sağlayan başka bir uygulama geliştirerek halk katılımına imkan veren ve böylece 3B modelin kalitesini artıran, deneysel geçici rekonstrüksiyon alternatiflerinin doğrudan yapı arazinde sunulmasıyla imar aşamasından önce karar verme sürecinin daha etkin ilerleyebilmesine olanak tanıyan farklı bir yaklaşım olması açısından önem arz eder.

\section{KAYNAKLAR}

1. Bloom, J.M., 2012. The Minaret, Edinburgh: Edinburgh University Press.

2. Bloom, J.M., 1991. Creswell and the Origins of the Minaret, Muqarnas, no. 8, 55-58.

3. Salah Haj İsmail, E.M., 2014. Post Conflict Conservation or Reconscuction: Analysis, Criteria, Values of the Recent Syrian Cultural Heritage, in ReUSO $2^{\circ}$ Convegno Internazionale Sulla Documentazione, Conservazione e Recupero del Patrimonio Architettonico e Sulla Tutela Paesaggistica, Floransa.

4. Alzaed, A., 2015. Sustainable Minarets: Towards Multifunctional Applications as a New Conceptual Design Model, International
Journal of Emerging Research in Management \&Technology, vol. 12, no. 4, 18-24.

5. Alafandi R., Abdul Rahim, A., 2014. Umayyad Mosque in Aleppo Yesterday, Today and Tomorrow, International Journal of Arts \& Sciences, 319-325.

6. Ismail, S.H., 2012. Reviewing Aleppo Public Spaces in Terms of Creativity and Co-Living, in Joint Urban design Workshop- Urban Design in Historic Context, Cairo.

7. ICOMOS, 1982. Declaration of Dresden on the Reconstruction of Monuments Destroyed by War, ICOMOS, Dresden.

8. Karabacak, S.B.A.H., 1981. Sahib Ata Fahrü' ddin Ali'nin Konya, İmaret ve Sivas Gökmedrese Vakfiyeleri, VD, vol. 13, 31-69.

9. Uğur, M.F., Koman M.M., 1939. Sahip Ata ile Oğullarının Hayatı ve Eserleri, İstanbul: Türkiye Matbaası.

10. Akok, M., 1970. Konya'da İnce Minareli Medrese, Türk Arkeoloji Dergisi, vol. 1, no. 19, 5-36, 1970.

11. Yavaş, D., Çobanoğlu, A., 2000. İnce Minareli Medrese, TDV İslam Ansiklopedis, vol. 22, 269-270.

12. Elsevier, 2013. Special Issue on the Applications of Augmented Reality in Architecture, Engineering, Automation in Construction, no. 33, 1-2.

13. Fangi, G., Wahbeh, W., 2013. The Destroyed Minaret of Umayyad Mosque of Aleppo, the Survey of the Original State, European Scientific Journal, Special Edition 4, 403-409.

14. Saggio G., Borra, D., 2011. Augmented Reality for Restoration/Reconstruction of Artefacts with Artistic or Historical Value, in Augmented Reality-Some Emerging Application Areas, A.Y.C. Nee, Ed., Shanghai, InTech, 59-86.

15. Amir, H., Behzadan, A., Vineet R. Kamat., 2013. Enabling Discovery-based Learning in Construction using Telepresent, Automation in Construction, no. 33, 3-10.

16. Snavely, N., Seitz, S., Szeliski, R., 2008. Modeling the World from Internet Photo Collections, International Journal of Computer Vision, vol. 80, no. 2, 189-210.

17. Furukawa, Y., Jean, P., 2010. Accurate, Dense, and Robust Multiview Stereopsis, IEEE Trans. 
Pattern Anal. Mach. Intell., vol. 32, no. 8, 1362-1376.

18. Kazhdan, M., Bolitho, M., Hoppe, H., 2006. Poisson Surface Reconstruction, in Proceedings of the Fourth Eurographics Symposium on Geometry Processing, Cagliari.

19. Fuhrmann, S., Goesele, M., 2014. Floating Scale Surface Reconstruction, ACM Trans. Graph., vol. 33, no. 4, 46:1-46:11.

20. Agarwal, S., Furukawa, Y., Snavely, N., Simon, I., Curless, B., Seitz, S.M., Szeliski, R., 2011. Building Rome in a Day, Commun. ACM, vol. 54, no. 10, 105-112.

21. Bulbul, A., Dahyot, R., 2017. Social Media Based 3D Visual Popularity, Computers \& Graphics.

22. Sinha, S.N., Steedly, D., Szeliski, R., Agrawala M., Pollefeys, M., 2008. Interactive 3D Architectural Modeling from Unordered Photo Collections, ACM Trans. Graph., vol. 27, no. 5, 159:1-159:10.

23. Martin-Brualla, R., Gallup, D., Seitz, S.M., 2015. 3D Time-lapse Reconstruction from Internet Photos, in Proceedings of the IEEE International Conference on Computer Vision.

24.Zandbergen, P.A., 2009. Accuracy of iPhone Locations: A Comparison of Assisted GPS, WiFi and Cellular Positioning, Transactions in GIS, vol. 13, 5-25.

25. Wu, C., 2013. Towards Linear-Time Incremental Structure from Motion, in Proceedings of the 2013 International Conference on 3D Vision.

26. Lowe, D.G., 1999. Object Recognition from Local Scale-invariant Features, in the Proceedings of the Seventh IEEE International Conference on Computer Vision. 